\title{
Comparing Chemical and Enzymatic Hydrolysis of Whey Lactose to Generate Feedstocks for Haloarchaeal Poly(3-hydroxybutyrate-co-3- hydroxyvalerate) Biosynthesis
}

\author{
Martin Koller ${ }^{1,2^{*}}$, Dario Puppi ${ }^{3}$, Federica Chiellini ${ }^{3}$, Gerhart Braunegg ${ }^{2}$ \\ ${ }^{1}$ University of Graz, Research Management and Service, c/o Institute of Chemistry, NAWI Graz, Heinrichstrasse 28, A-8010 Graz, Austria \\ ${ }^{2}$ ARENA - Association for Resource Efficient and Sustainable Technologies, Inffeldgasse 23, 8010 Graz, Austria \\ ${ }^{3}$ BIOLab Research Group, Department of Chemistry \& Industrial Chemistry, University of Pisa, UdR INSTM Pisa, Via Moruzzi, 13 - 56124 - Pisa, \\ Italy
}

\begin{abstract}
Whey lactose was hydrolyzed via different biocatalytic and chemical methods in order to establish the optimum procedure to generate a carbon-rich substrate for haloarchaeal production of the biopolyester poly (3-hydroxybutyrate-co-3-hydroxyvalerate) (PHBHV).

Biocatalytic hydrolysis was carried out using the commercially available bacterial $\beta$-galactosidase enzyme formulation Maxilact LG $2000^{\mathrm{TM}}$ and solid fungal $\beta$-galactosidase from Aspergillus niger. Different enzyme concentrations, incubation times, temperatures and $\mathrm{pH}$-ranges were investigated to assess the optimum hydrolysis conditions. As major outcome of the undertaken investigation, an addition of $0.25 \%$ (v/v) Maxilact LG $2000^{\mathrm{TM}}$ to whey permeate at $\mathrm{pH}$-value 6.5 and $38^{\circ} \mathrm{C}$ leads to almost complete (more than $90 \% \mathrm{w} / \mathrm{w}$ ) lactose hydrolysis already after only $5 \mathrm{~h}$ of stirring, and performs beneficial in terms of hydrolysis kinetics compared to the solid enzyme formulation. As an inexpensive alternative, kinetics of hydrolysis of whey lactose was investigated using different amounts of $\mathrm{HCl}$ or $\mathrm{H}_{2} \mathrm{SO}_{4}$, respectively, at $90^{\circ} \mathrm{C}$. By adjusting the $\mathrm{pH}$-value to 0.7 or lower and stirring at $90^{\circ} \mathrm{C}$ for $5 \mathrm{~h}$, a degree of hydrolysis of about $90 \%(\mathrm{w} / \mathrm{w})$ was achieved.

The hydrolysis matter was used as carbon sources for PHBHV bioproduction by the haloarchaeal species Haloferax mediterranei. Independent of the applied hydrolysis method, PHBHV biopolyesters of similar monomeric composition, molar mass and dispersity index Di were accumulated by the strain. The final decision of the most adequate method in future will depend upon the microbial production strain and production scale.
\end{abstract}

\section{Mathematical Notations \\ Degree of hydrolysis $=\frac{\left[\text { Lactose }_{\text {start }}\right]-\left[\text { Lactose }_{\text {end }}\right]}{\left[\text { Lactose }_{\text {start }}\right]}$ \\ Dispersity Index $D_{i}=\frac{M_{w}(\text { Weight average molar mass })}{M_{n}(\text { Number average molar mass })}$ \\ Conversion Yield $Y_{(P H A / \text { sugar })}=\frac{\text { produced PHA }\left[\frac{g}{L}\right]}{\text { converted sugar }\left[\frac{g}{L}\right]}$ \\ 1 katal $=\frac{\text { Hydrolysis of } 1 \mathrm{Mol} \text { Lactose }}{\sec . L}$ \\ Introduction \\ hydroxyalkanoic- or, rather scarcely, hydroxyalkenoic acids can act as thermoplastic or elastomeric bulk polymers. They are suitable for producing packaging items, or as raw materials in bioinspired niche fields of application, e.g., in the broad medical, pharmaceutical or surgical arena [1-6]. Despite all efforts to finally make PHA production economically competitive, the rather high production cost still restricts their ultimate market breakthrough. To a significant extent, these costs emanate from the carbon substrate needed as feedstock for PHA-accumulating microorganisms [6]. As a way out, a great deal of research activities nowadays is focused on the application of carbonaceous industrial surplus streams as feedstocks. Just to mention a few, current literature makes us familiar with PHA biosynthesis starting from crude glycerol [7,8], from hydrolyzed polysaccharides $[9,10]$, carbon dioxide from industrial effluent gases $[11,12]$, other C1 compounds [13], waste lipids [14,15], or, as item of interest in the article at hand, lactose from dairy surplus whey [16].}

Nowadays, solutions to reduce the current quantities of fullcarbon backbone plastics of petrochemical origin represent a major global issue for both academic research and industrial innovation. In this context, selected biopolymers are of special interest because they display plastic-like properties and, in parallel, address the following attributes: based on renewable resources ("biobased" nature), biomediated conversion of the raw materials to the polymer, biodegradability and/or compostability of the polymer and derived plastic items; finally, biocompatibility of the polymer is crucial especially for in vivo application. Nature provides such target products; e.g., microbial poly(hydroxyalkanoate)s (PHA) play a prime role in various fields of application. These homo-, co- or terpolyesters of

Whey accrues in various global regions at quantities by far surmounting the market needs for classical applications such as fodder, baby nutrition, or ingredients for pharmaceutical products. "Corresponding Author: Dr. Martin Koller, University of Graz, Research Management and Service, c/o Institute of Chemistry, NAWI Graz, Heinrichstrasse 28, A-8010 Graz, Austria; E-mail: martin.koller@uni-graz.at

Citation: Koller M, Puppi D, Chiellini F, Braunegg G (2016) Comparing Chemical and Enzymatic Hydrolysis of Whey Lactose to Generate Feedstocks for Haloarchaeal Poly(3-hydroxybutyrate-co-3-hydroxyvalerate) Biosynthesis. Int J Pharma Sci Res 3: 112. doi: http://dx.doi.org/10.15344/2394-1502/2016/112

Copyright: (C) 2016 Koller et al. This is an open-access article distributed under the terms of the Creative Commons Attribution License, which permits unrestricted use, distribution, and reproduction in any medium, provided the original author and source are credited. 
Citation: Koller M, Puppi D, Chiellini F, Braunegg G (2016) Comparing Chemical and Enzymatic Hydrolysis of Whey Lactose to Generate Feedstocks for Haloarchaeal Poly(3-hydroxybutyrate-co-3-hydroxyvalerate) Biosynthesis. Int J Pharma Sci Res 3: 112. doi: http://dx.doi.org/10.15344/2394-1502/2016/112

Page 2 of 8

Only for the European Union, estimations quantify the annual whey production with more than $40 \mathrm{Mt}$ per year, corresponding to more than $2 \mathrm{Mt}$ of lactose; thereof, a considerable share is currently disposed into marine environments, provoking considerable ecological threats by its high biochemical oxygen demand [16-22]. Hence, new (bio) products from whey are aspired, especially such as those produced by the action of either Gram-positive or Gram-negative microbial production strains $[16,23]$. Investigation of whey-based PHA biosynthesis started almost 20 years ago and encompassed the implementation of both Gram-negative wild type strains like Haloferax mediterranei [17] Sinorhizobium meliloti [24], Hydrogenophaga pseudoflava [17,24,25], Pseudomonas hydrogenovora [18], or Methylobacterium sp. [26], and genetically engineered Gram-negative organisms, predominately Escherichia coli $[27,28]$ and Cupriavidus necator [29]. The investigation of Gram-positive organisms for whey-based PHA production is still in its infancy and restricted to a scarce number of reports [20].

As a remarkable feature, the haloarchaeon $H$. mediterranei produces the high-value PHA copolyester poly(3-hydroxybutyrateco-3-hydroxyvalerate) (PHBHV) from lactose-derived sugars without the need for structurally related 3-hydroxyvalerate $(3 \mathrm{HV})$ precursors [17] normally required for PHBHV biosynthesis [30, 31]. This metabolic particularity is based on the strain's multiple propionylCoA generating pathways [32,33]. All other strains listed above convert lactose and/or its hydrolysis products into the rather brittle thermoplastic homopolyester poly(3-hydroxybutyrate) (PHB). Apart from whey lactose, $H$. mediterranei was reported to produce $\mathrm{PHBHV}$ from a range of additional inexpensive carbon-rich materials of agroindustrial origin, such as crude glycerol phase [8], extruded rice bran and starch [34], vinasse [35], or stillage from ethanol distillation [36]. Recently, olive mill wastewater was utilized as inexpensive carbon source for PHBV production by $H$. mediterranei in one stage cultivation process [37]. For optimum growth and PHA production, this organism requires a $\mathrm{NaCl}$ concentration comprised between 100 and $200 \mathrm{~g} / \mathrm{L}$ [19]. This high salinity protects $H$. mediterranei cultivation setups from microbial contamination, and facilitates the recovery of PHA granules by subjecting cells to hypotonic conditions [6].

Hydrolysis of lactose by $\beta$-galactosidase (EC.3.2.1.23) is the first step in biological PHA production from whey. Some of the above listed PHA producing strains, also $H$. mediterranei, show no or insufficient activity of lactose utilization, but accept its hydrolysis products glucose and galactose as substrates $[17,22,38]$. Lactose can be hydrolyzed either chemically or enzymatically prior to the cultivation (Figure 1). Whereas chemical hydrolysis of lactose classically resorts to the application of the strong mineral acids $\mathrm{HCl}$ and $\mathrm{H}_{2} \mathrm{SO}_{4}$ under $\mathrm{pH}$-values below 1.5 and high temperatures up to $150^{\circ} \mathrm{C}$ [39], the biocatalyst $\beta$-galactosidase can be applied either as free enzyme $[22,40]$ or as immobilized enzyme on a commercial silica-alumina support [41]. The enzymatic hydrolysis reaction can be carried out in batch mode [4] or in continuously operated bed reactor systems [42]. Although a convenient method, cost estimations suggest that for large scale operations, enzymatic hydrolysis will be too expensive, thus alternatives like the acidic approach are needed [43].

\section{Aim of the Work}

We compared and optimized chemical and enzymatic hydrolysis of whey permeate lactose, and assessed the impact of the different hydrolysis methods on PHA production by the haloarchaeon $H$. mediterranei. Enzyme assays used were the commercial solution Maxilact LG $2000^{\mathrm{TM}}$ (contains bacterial $\beta$-galactosidase from Klyveromyces marxianus stabilized by dissolution in glycerol), and commercial solid fungal $\beta$-galactosidase powder obtained from Aspergillus niger. In order to round off the experimental series, also pure sugars (equimolar mixture of glucose and galactose) were tested as carbon source to enable a direct comparison.

Impact of the hydrolysis method was assessed by comparing the generated amounts of PHA, the composition of PHA on the monomeric level, yields of PHA from sugars, and molar mass distribution. The latter was of special interest because it is well known for other strains that, when diols or polyols are used as substrates, these substances cause termination of chain propagation by covalent linkage to the polymer's carboxyl terminus, thus resulting in PHA of lower molar masses [44]. Therefore, we intended to assess also the effect of glycerol, the enzyme solvent used in the Maxilact LG $2000^{\mathrm{TM}}$ assay, on the molar masses.

\section{Materials and Methods}

\section{The raw material whey permeate}

Sweet whey permeate was generated by ultrafiltration of whey fractions obtained as by-product of Asiago DOC cheese production. The permeate was provided with courtesy by the industrial project

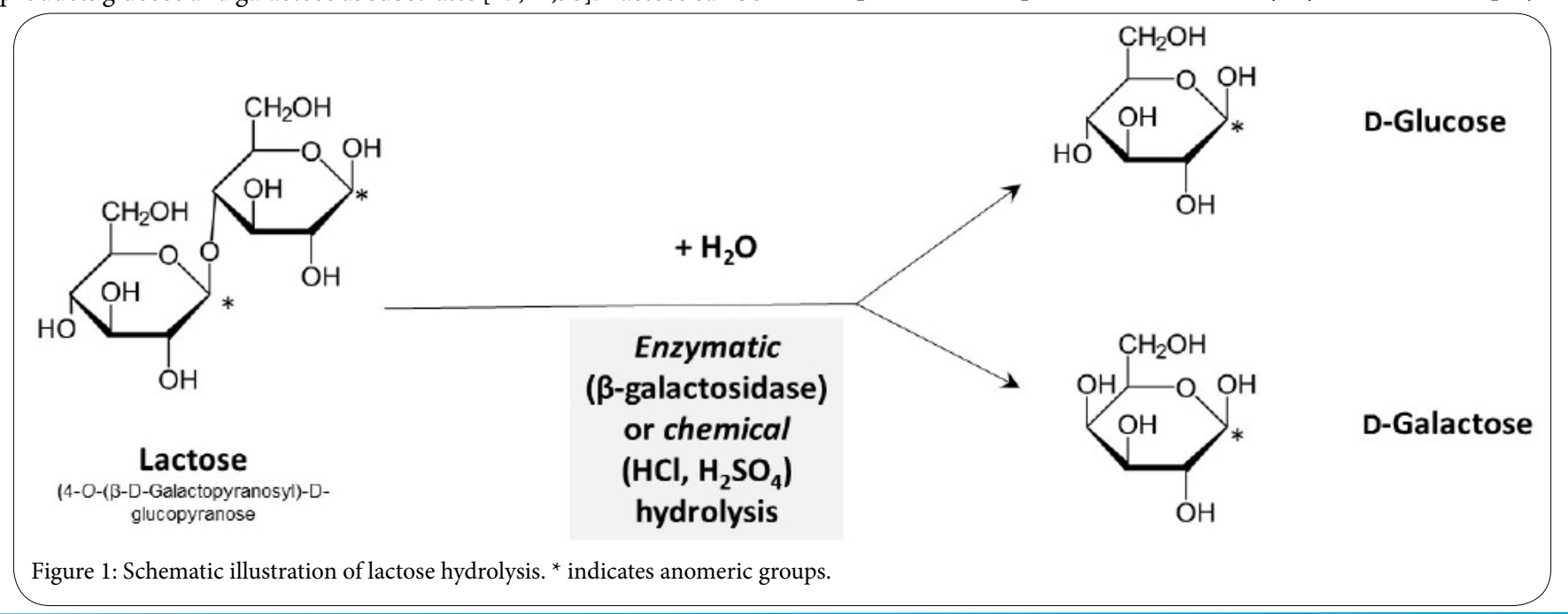


Citation: Koller M, Puppi D, Chiellini F, Braunegg G (2016) Comparing Chemical and Enzymatic Hydrolysis of Whey Lactose to Generate Feedstocks for Haloarchaeal Poly(3-hydroxybutyrate-co-3-hydroxyvalerate) Biosynthesis. Int J Pharma Sci Res 3: 112. doi: http://dx.doi.org/10.15344/2394-1502/2016/112

Page 3 of 8

partner Latterie Vicentine S.c.a., Veneto, Italy. The lactose content in the permeate determined via HPLC (method described previously [4]) amounted to $211 \mathrm{~g} / \mathrm{L}$.

\section{Optimization of enzymatic hydrolysis of Whey Lactose}

Two enzymatic assays were tested for their possible application to hydrolyse the high amounts of lactose in whey permeate: commercial solid $\beta$-galactosidase from Aspergillus niger (Sigma Aldrich ${ }^{\circ}$ ) and the commercial liquid assay Maxilact LG $2000^{\mathrm{TM}}$ obtained as donation from DSM Food Specialities", UK (manufacturer specification: "2,000 NLU/g; glycerol content about 50\%” [45]).

The activities of these enzymatic assays were determined via a standardized test using the reference substrate p-nitrophenyl- $\beta$-Dgalactopyranoside, a compound providing a yellow colouration after hydrolysis by $\beta$-galactosidase (method according to [46]) which can be monitored spectroscopically at $\lambda=400 \mathrm{~nm}$. This way, the activities of the two enzymatic assays were determined at $50^{\circ} \mathrm{C}$, a $\mathrm{pH}$-value of 5.8 , and an incubation time of 10 minutes.

The following activities were determined by hydrolysis of the reference substrate $\mathrm{p}$-nitrophenyl- $\beta$-D-galactopyranoside:

1 Unit (hydrolysis of $1,000 \mu \mathrm{M}$ substrate per minute under the conditions described above) corresponds to $2.9 \mu \mathrm{g}$ solid enzyme or $125 \mu \mathrm{L}$ Maxilact LG $2000^{\mathrm{TM}}$.

In order to find out the optimum conditions for hydrolysis of lactose in the matrix of the highly concentrated whey permeate, several series of hydrolysis experiments with different parameters ( $\mathrm{pH}$-value, temperature, solid enzyme from Aspergillus niger or Maxilact LG $2000^{\mathrm{TM}}$, concentration of enzymes, concentration of substrate, whey or solution of lactose) were carried out. $100 \mathrm{~mL}$ of whey permeate or concentrated lactose solution were adjusted to different $\mathrm{pH}$-values (4.0 to 7.0$)$ and incubated at different temperatures $\left(30-60^{\circ} \mathrm{C}\right)$ for 25.25 hours.

\section{Optimization of acidic hydrolysis of whey lactose}

$100 \mathrm{~mL}$ samples of whey permeate were adjusted to extremely low $\mathrm{pH}$-values (1.5, 0.9, 0.7, and 0.6) using $\mathrm{HCl}\left(\right.$ Merck $^{\star}, 37 \%$ $\mathrm{w} / \mathrm{w})$ or $\mathrm{H}_{2} \mathrm{SO}_{4}\left(\right.$ Merck $\left.^{\oplus}, 98 \% \mathrm{w} / \mathrm{w}\right)$, respectively. Under continuous stirring (heated magnetic stirrer), whey lactose was hydrolysed at a temperature of $90^{\circ} \mathrm{C}$. The proceeding hydrolysis was monitored via HPLC4 to determine the decline in lactose concentration as well as the increase of glucose and galactose.

\section{Microbial production strain}

H. mediterranei DSM 1411 was purchased as lyophilized culture sample from DSMZ culture collection (Braunschweig, Germany). Strain maintenance was done on agar slants (medium composition vide infra) which were stored at $4^{\circ} \mathrm{C}$. Colonies were transferred to fresh slants in three week intervals.

\section{Media and culture conditions}

Cultivations were carried out in $300 \mathrm{~mL}$ baffled shaking flasks containing $100 \mathrm{~mL}$ saline nutrient medium under continuous shaking in a laboratory incubator at $\mathrm{T}=37^{\circ} \mathrm{C}$ and $180 \mathrm{rpm}$. The highly saline nutrient medium was composed as follows (g/L): $\mathrm{NaCl}, 120 ; \mathrm{MgSO}_{4}$ • $6 \mathrm{H}_{2} \mathrm{O}, 10.4 ; \mathrm{KCl}, 3.2 ; \mathrm{CaCl}_{2} \bullet 2 \mathrm{H}_{2} \mathrm{O}, 0.5 ; \mathrm{NaBr}, 0.5 ; \mathrm{MgSO}_{4} \bullet 7 \mathrm{H} \mathrm{O}, 16$;
$\mathrm{NaHCO}_{3}, 0.2$; yeast extract, 2.5 ; casein hydrolysate, 2.5 ; trace elements solution SL 6 [47], 1; carbon source, 10 (calculated for sum of glucose and galactose). The $\mathrm{pH}$-value of the cultivation media was adjusted to 7.0. All cultivation setups were investigated in duplicate. After $48 \mathrm{~h}$ of cultivation, a refeed of plus $10 \mathrm{~g} / \mathrm{L}$ carbon source was accomplished under sterile conditions for all setups.

\section{Optical density determination}

Microbial growth was monitored during the experiments by measuring the optical density at $\lambda=420 \mathrm{~nm}$; cell-free supernatant was used as zero-reference. Samples and reference were measured in $1 \mathrm{~mL}$ plastic cuvettes (Greiner Co. ${ }^{\circledR}$, Germany) using a Spectronic genesys 2 PC spectrophotometer. If needed, samples were diluted with $15 \%$ $\mathrm{NaCl}$ solution (physiological $\mathrm{NaCl}$ solution was avoided in order to prevent cell disrupture).

\section{PHA analysis via GC-FID}

$5 \mathrm{~mL}$ of fermentation broth was centrifuged at $4^{\circ} \mathrm{C}$ and $12,000 \mathrm{~g}$ (Megafuge 1.0R Heraeus Sepatech) in tightly lockable glass tubes. The supernatant was used for substrate (sugar) analysis via HPLC (vide supra) as previously reported [4], whereas the remaining biomass pellet was frozen and lyophilized for $24 \mathrm{~h}$ (freeze-dryer Christ Alpha 1-4 B). Intracellular PHA in lyophilized biomass pellets was dissolved and transesterificated into volatile 3-hydroxylkanoatemethyl esters (3HAME) via acidic methanolysis in a one-pot reaction following a method adapted from Braunegg et al. [48]: $2 \mathrm{~mL}$ of a transesterification mixture, consisting of $\mathrm{CH}_{3} \mathrm{OH}(95.15 \% \mathrm{v} / \mathrm{v}), \mathrm{H}_{2} \mathrm{SO}_{4}$ $(4.75 \% \mathrm{v} / \mathrm{v})$ and the internal standard hexanoic acid $(0.10 \% \mathrm{v} / \mathrm{v})$ were added to the lyophilized pellets, together with $2 \mathrm{~mL}$ of the solvent $\mathrm{CHCl}_{3}$. After tightly locking the tubes, the incubation was carried out for $3.5 \mathrm{~h}$ at $98^{\circ} \mathrm{C}$ in a thermostated water bath under continuous shaking. After cooling the tubes, $1 \mathrm{~mL}$ of aqueous $\mathrm{NaHCO}_{3}$ solution was added $\left(\mathrm{NaHCO}_{3}\right.$ solution was used instead of pure water in order to protect the GC-column by lowering the acidity of the sample [15]); after intensive vortexing and subsequent centrifugation for phase separation, the organic phase was subjected towards analysis of 3HAMEs using a HP 5890 Series II gas chromatograph (GC; $30 \mathrm{~m}$ HP 5 column, protected by a $5 \mathrm{~m} \mathrm{HP} 1$ capillary pre-column) according to the protocol described by previously [14]. 3HAMEs (methyl esters of PHA building blocks $3 \mathrm{HB}$ and $3 \mathrm{HV}$ ) were registered by a flame ionization detector, the carrier gas helium was used with a split-ratio of 1:10. As reference, pure PHBHV (ICI ${ }^{\oplus}$, UK; $3 \mathrm{HV}$ mass fraction $m$ $=0.191 \mathrm{~g} / \mathrm{g}$ ) was used as standard. The determinations were done in duplicate.

\section{Polymer recovery}

Cells cultivated in shaking flasks were in situ pasteurized $\left(80^{\circ} \mathrm{C}\right.$, $30 \mathrm{~min}$ ), centrifuged (12,000 g, $20 \mathrm{~min}$., Sorvall RC-5B Refrigerated Superspeed centrifuge), frozen, and lyophilized ( $24 \mathrm{~h}$ in freezedryer Christ Alpha ${ }^{\circ}$ 1-4 B) until constant mass was achieved. After degreasing the biomass by overnight Soxhlet extraction with $\mathrm{C}_{2} \mathrm{H}_{5} \mathrm{OH}$ (turned out to results in a more complete degreasing within the same time; results not shown) and subsequent drying at RT, PHA was overnight Soxhlet-extracted from degreased biomass with $\mathrm{CHCl} 3$. The volume of the obtained solution of $\mathrm{PHA}$ in $\mathrm{CHCl}_{3}$ was reduced by about $90 \%$ by using a rotary evaporator (Büchi ${ }^{\circledR}$ Rotavapor RE111, Switzerland). From the remaining viscous solution, the polymer was precipitated by dropping the solution into the tenfold amount of iced ethanol under continuous stirring, recovered via vacuum filtration, 
Citation: Koller M, Puppi D, Chiellini F, Braunegg G (2016) Comparing Chemical and Enzymatic Hydrolysis of Whey Lactose to Generate Feedstocks for Haloarchaeal Poly(3-hydroxybutyrate-co-3-hydroxyvalerate) Biosynthesis. Int J Pharma Sci Res 3: 112. doi: http://dx.doi.org/10.15344/2394-1502/2016/112

Page 4 of 8

and finally air dried at RT. The purity of the extracted materials and the completeness of the extraction was determined by GC analysis (vide supra) of the isolated PHA and the remaining biomass.

\section{Polymer characterization}

Molar mass data (weight average molar mass $M_{w}$, number average molar mass $M_{n}$ ) of extracted PHA samples were determined according to a previously described standard protocol [31] by using a Jasco ${ }^{\circ} \mathrm{PU}$ 1580 HPLC equipped with a Jasco 830-RI detector and two PLgel 5 $\mu \mathrm{m}$ MIXED-C columns. Solvent: Chloroform at a flow rate $1.0 \mathrm{~mL}$ min-1, standards for external calibration: mono-disperse polystyrene. Dispersity index Di was determined according to the mathematical notations list.

\section{Results and Discussion}

\section{Enzymatic hydrolysis}

It turned out that temperature ranges of $45^{\circ} \mathrm{C}$ for the solid enzyme and $38^{\circ} \mathrm{C}$ for Maxilact LG $2000^{\mathrm{TM}}$, together with $\mathrm{pH}$-value conditions of 4.8 (solid enzyme) and 6.5 (Maxilact LG 2000 ${ }^{\mathrm{TM}}$ ) constitute the optimum values for enzymatic lactose hydrolysis in whey permeate. These hydrolysis products were used for the cultivation experiments.

Figure 2a shows the time course of hydrolysis of lactose in concentrated whey permeate by using two different concentrations of both the solid enzyme and Maxilact LG $2000^{\mathrm{TM}}$ under optimized conditions (see prior paragraph). In order to illustrate these data more concretely, the remaining concentrations of lactose are depicted in Figure $2 \mathrm{~b}$. Figure $2 \mathrm{c}$ shows the hydrolysis rates for lactose degradation in $\mathrm{mMol} / \mathrm{L}$. Highest hydrolysis rates occur at the beginning of the incubation. Therefore, Figure $2 \mathrm{~d}$ compares the initial enzymatic activities during the first hour of cultivation, expressed in the SI-unit katal (1 katal hydrolyses $1 \mathrm{Mol}$ Lactose / (sec $\bullet$ L).

\section{Chemical hydrolysis}

Figures 3a,b illustrate the hydrolysis curves at $\mathrm{T}=90^{\circ} \mathrm{C}$. For both acids, a $\mathrm{pH}$-value of 1.5 is not acidic enough for a sufficient lactose hydrolysis; only $37 \%(\mathrm{HCl})$ and $29 \%\left(\mathrm{H}_{2} \mathrm{SO}_{4}\right)$ of lactose hydrolysis were achieved. Better values were obtained at a $\mathrm{pH}$-value of 0.9 ; a degree of hydrolysis of about $70 \%$ (hydrolysis with $\mathrm{HCl}$ ) was obtained. Under even stronger acidic conditions ( $\mathrm{pH}$-value 0.6 or 0.7 ), a degree of hydrolysis of about $90 \%$ was achieved for both $\mathrm{HCl}$ and $\mathrm{H}_{2} \mathrm{SO}_{4}$. Using $\mathrm{H}_{2} \mathrm{SO}_{4}$, only $69 \%$ of lactose was hydrolyzed at a $\mathrm{pH}-$ value of 0.9 even after 21.2 hours of hydrolysis treatment. Therefore, it can be concluded that using $\mathrm{HCl}$ or $\mathrm{H}_{2} \mathrm{SO}_{4}$, respectively, almost identical degrees of hydrolysis are obatine at the same $\mathrm{pH}$-values. Consequently, whey permeate has to be acidified to $0.7 \mathrm{pH}$ or lower for almost complete hydrolysis of whey lactose. The final degrees of lactose hydrolysis as attained after 21.2 hours by application of $\mathrm{HCl}$ and $\mathrm{H}_{2} \mathrm{SO}_{4}$, respectively, are compared in Figure 3 .

\section{Cultivation of $H$. mediterranei on differently hydrolysed whey lactose}

Figuress 4 (a-f) show that acidic hydrolysis does not cause any negative influence on growth of Haloferax mediterranei when compared to the utilization of enzymatic hydrolysates or pure sugars. (Figure $4 \mathrm{~d}$ ) Time courses of optical density [ $\lambda=420 \mathrm{~nm}$ ], $\mathrm{pH}$-value and substrates were monitored. In addition, it is important to mention
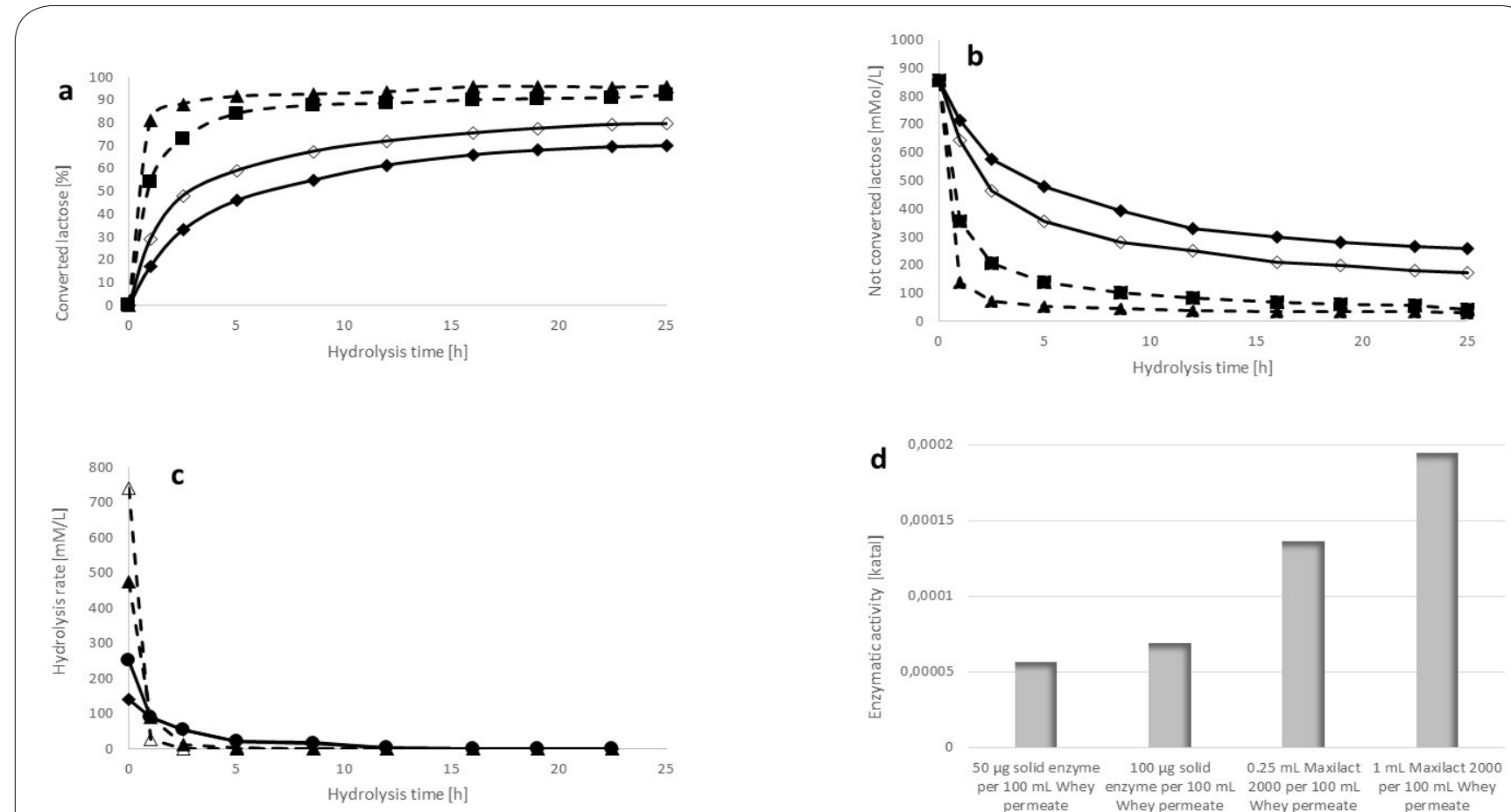

Figure 2: Hydrolysis of lactose in whey permeate: Application of two different enzymatic assays (solid $\beta$-galactosidase: $\mathrm{pH}$-value $=4.8, \mathrm{~T}=45^{\circ} \mathrm{C}$; Maxilact LG $2000^{\mathrm{TM}}$ : $\mathrm{pH}$-value $=6.5, \mathrm{~T}=38^{\circ} \mathrm{C}$ ). (a) Degree of lactose conversion vs. time; (b) remaining concentration of lactose vs. time; (c) hydrolysis velocity vs. time (d) initial enzymatic activity.

$-50 \mathrm{mg}$ solid $\beta$-galactosidase per $100 \mathrm{~mL}$ whey permeate, $\_-100 \mathrm{mg}$ solid $\beta$-galactosidase per $100 \mathrm{~mL}$ whey permeate, - - -2 - $0.25 \mathrm{~mL}$ Maxilact $^{\circledast} \mathrm{LG} 2000^{\mathrm{TM}}$ per $100 \mathrm{~mL}$ whey permeate, _ $\Delta-1 \mathrm{~mL}$ Maxilact ${ }^{\circledast} \mathrm{LG} 2000^{\mathrm{TM}}$ per $100 \mathrm{~mL}$ whey permeate 
Citation: Koller M, Puppi D, Chiellini F, Braunegg G (2016) Comparing Chemical and Enzymatic Hydrolysis of Whey Lactose to Generate Feedstocks for Haloarchaeal Poly(3-hydroxybutyrate-co-3-hydroxyvalerate) Biosynthesis. Int J Pharma Sci Res 3: 112. doi: http://dx.doi.org/10.15344/2394-1502/2016/112

Page 5 of 8

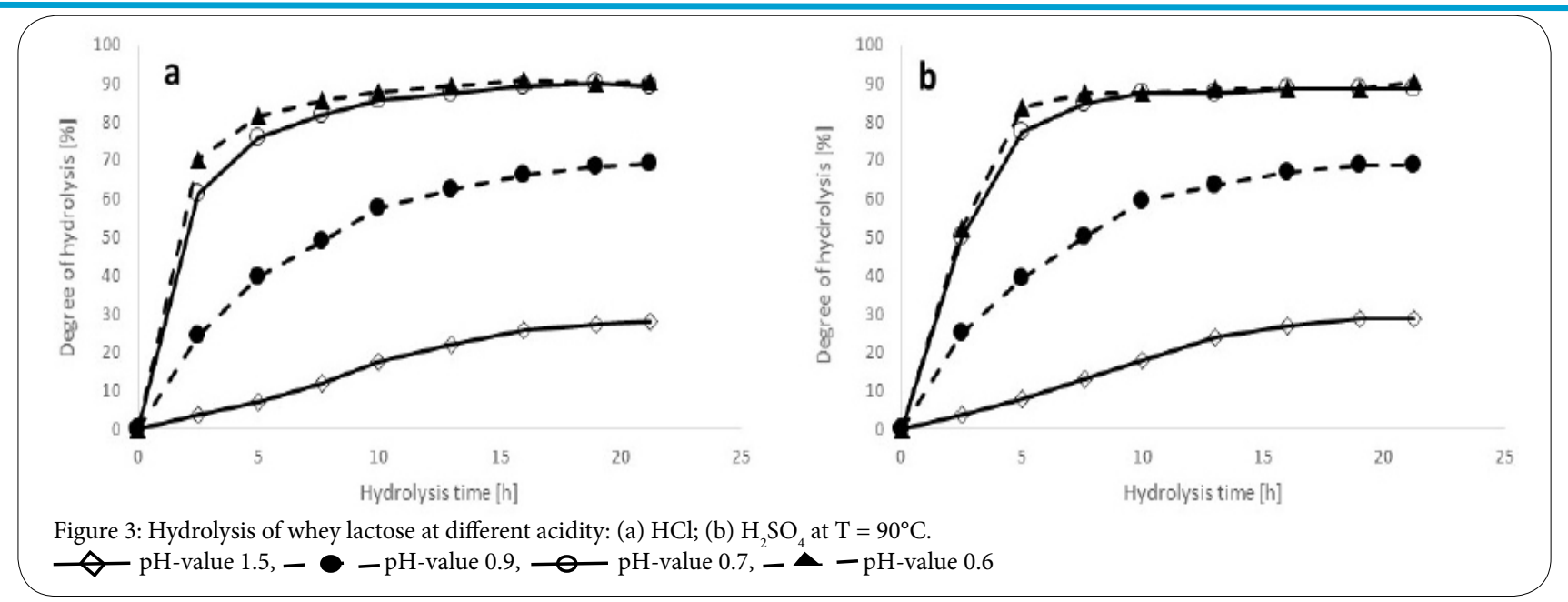

that, using acidic hydrolysis conditions, no degradative loss of sugars was observed (Figures $4 \mathrm{c}$,d). Table 1 collects the data for polymers obtained from these cultivations; here, the final concentration of PHA, the composition on the monomeric level and molar mass distribution were investigated. As described before, the application of solid $\beta$-galactosidase from $A$. niger (Figure 4c) did only insufficiently hydrolyze lactose (see also Figure 2), therefore, high amounts of lactose which is not accepted by the production strain remained in the medium, constituting an undesired substrate loss.

Along all experimental set-ups, growth rate was in the same range (see time curves for optical density, Figures 4 (a-f). Investigating the conversion rates of sugars to PHA, all experimental set-ups based on whey-derived substrates, showed similar yields $(0.16-0.25 \mathrm{~g} / \mathrm{g})$; the yields from pure sugars were significantly lower $(0.10 \mathrm{~g} / \mathrm{g}$; see Table 1$)$. It is also obvious that, at each cultivation setup, glucose is the preferred carbon source compared with galactose, which is in accordance with the recent findings of Pais et al. [38].

\begin{tabular}{|c|c|c|c|c|c|}
\hline Whey lactose hydrolyzed by: & PHA after 120 hours [g/L] & m (3HV/PHA) [\%] & Yield (PHA/sugar) & $M_{w}(\mathrm{kDa})$ & $D_{i}$ \\
\hline Maxilact LG $2000^{\mathrm{TM}}\left(\mathrm{pH}\right.$-value $\left.6.5 ; \mathrm{T}=38^{\circ} \mathrm{C}\right)$ & $5.23 \pm 0.43$ & $7.9 \pm 0.1$ & $0.25 \pm 0.07$ & $769 \pm 5$ & 1.95 \\
\hline$\beta$ - Galactosidase from Aspergillus niger & $4.67 \pm 0.32$ & $8.9 \pm 0.3$ & $0.20 \pm 0.02$ & $626 \pm 18$ & 2.10 \\
\hline Glucose \& Galactose (equimolar mixture of pure sugars) & $4.77 \pm 0.05$ & $11.5 \pm 0.1$ & $0.10 \pm 0.00$ & $878 \pm 22$ & 2.45 \\
\hline $\mathrm{HCl}\left(\mathrm{pH}\right.$-value $\left.0.6 ; \mathrm{T}=90^{\circ} \mathrm{C}\right)$ & $5.18 \pm 0.07$ & $10.6 \pm 0.3$ & $0.16 \pm 0.01$ & $680 \pm 54$ & 2.50 \\
\hline $\mathrm{H}_{2} \mathrm{SO}_{4}\left(\mathrm{pH}\right.$-value $\left.0.6 ; \mathrm{T}=90^{\circ} \mathrm{C}\right)$ & $3.76 \pm 0.11$ & $11.0 \pm 0.0$ & $0.18 \pm 0.01$ & $686 \pm 44$ & 3.10 \\
\hline
\end{tabular}

Table 1: Polymer data for PHAs from cultivations on whey lactose hydrolyzed via different methods ( \pm refer to the deviation between two parallel cultivations).

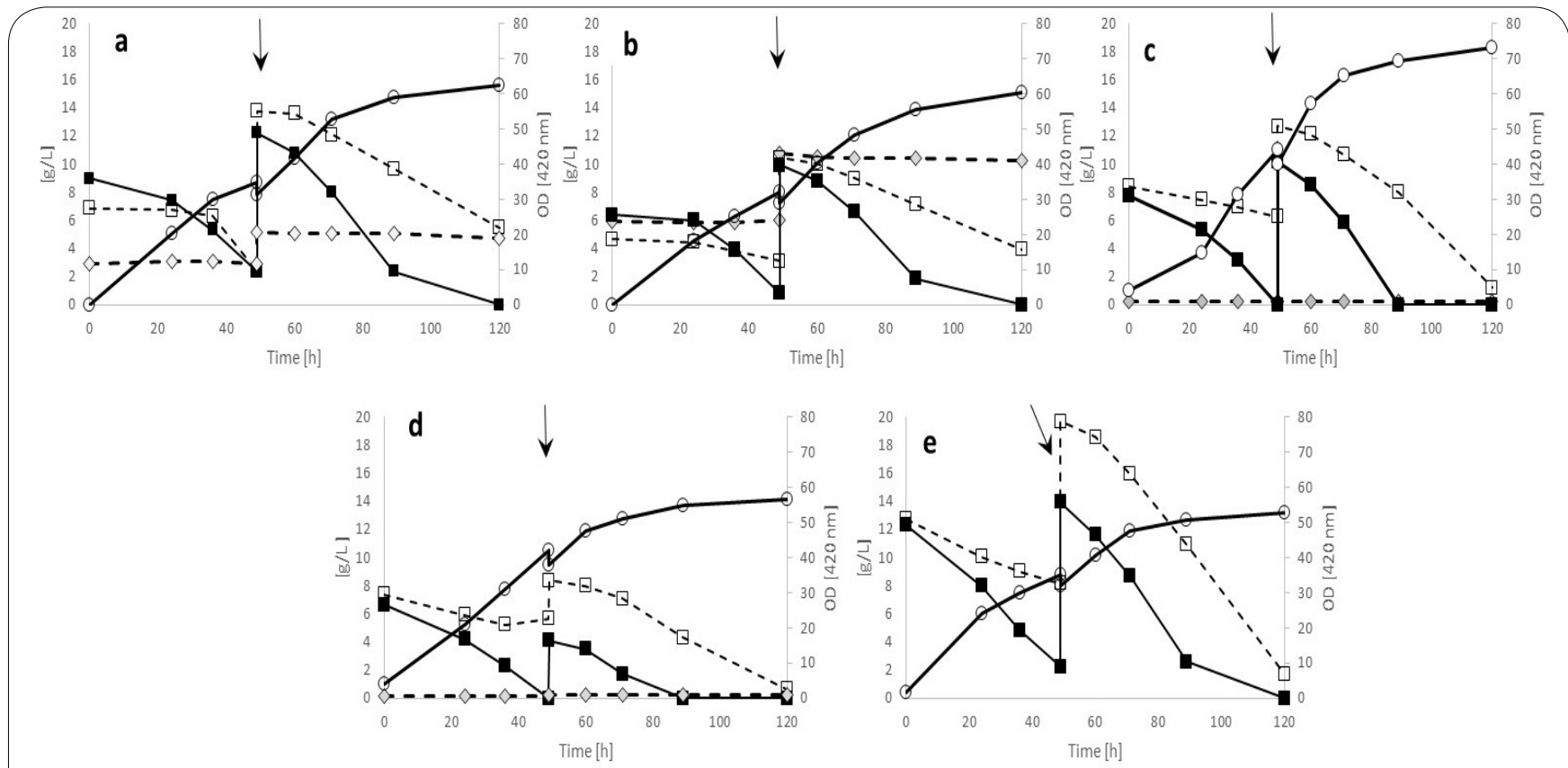

Figure 4: Time courses of sugars and growth curve: $H$. mediterranei on whey lactose hydrolyzed via different techniques. (a) Maxilact LG 2000 ${ }^{\mathrm{TM}}$, (b) solid enzyme from $A$. niger, $(c)$ hydrolysis with $\mathrm{HCl},(d)$ hydrolysis with $\mathrm{H}_{2} \mathrm{SO}_{4},(e)$ artificial substrate: equimolar mixtures of glucose and galactose. The arrows indicate the refeed with substrate. 
Citation: Koller M, Puppi D, Chiellini F, Braunegg G (2016) Comparing Chemical and Enzymatic Hydrolysis of Whey Lactose to Generate Feedstocks for Haloarchaeal Poly(3-hydroxybutyrate-co-3-hydroxyvalerate) Biosynthesis. Int J Pharma Sci Res 3: 112. doi: http://dx.doi.org/10.15344/2394-1502/2016/112

Page 6 of 8

\begin{abstract}
Polymer Characterization
It is visible from Table 1 that the highest values for weight average molar masses are obtained, if pure sugars are applied as carbon source (878 kDa, $\left.D_{i} 2.45\right)$. The small amounts of glycerol included in the liquid enzyme assay Maxilact LG $2000^{\mathrm{TM}}$ do not negatively influence molar mass of the produced PHA $\left(769 \mathrm{kDa}, D_{i} 1.95\right)$ in direct comparison with chemically (acidic) hydrolyzed whey lactose $(\mathrm{HCl}$ $\left.680 \mathrm{kDa}, D_{i} 2.50 ; \mathrm{H} 2 \mathrm{SO} 4: 686 \mathrm{kDa}, D_{i} 3.10\right)$. The application of solid enzyme from $A$. niger resulted in similar molar masses $\left(M_{w}=630 \mathrm{kDa}\right.$; $\left.D_{i} 2.10\right)$ if compared with the other hydrolysis methods. Dispersity indices $\left(D_{i}\right)$ were favourably low and in the same order of magnitude for all experimental set-ups ( $D_{i}$ ranging from 1.95 to 3.1 ).
\end{abstract}

\section{Comparative analysis of the results}

According to the results, the addition of $0.25 \mathrm{~mL}$ Maxilact LG $2000^{\mathrm{TM}}$ per litre whey permeate at a $\mathrm{pH}$-value of 8.5 at $38^{\circ} \mathrm{C}$ is a viable method for hydrolysis of lactose in highly concentrated whey permeate, resulting in a degree of hydrolysis exceeding $90 \%(w / w)$ after only $5 \mathrm{~h}$ of stirring; this is considerably faster than value reported for lactose hydrolysis by free Kluyveromyces fragilis $\beta$-galactosidase, as previously reported by Roy and Gupta, who obtained a comparable degree of hydrolysis only after $48 \mathrm{~h}$ [42]. Here, it has to be emphasized that these authors were able to reach degrees of hydrolysis competitive with our setup with Maxilact LG $2000^{\mathrm{TM}}$ by immobilizing the enzyme on cellulose beads by epichlorohydrin coupling chemistry, and operating the process in a fluidized bed reactor. Application of the solid enzyme from $A$. niger is not advantageous due to the low hydrolysis rates achieved in our setups even at rather high concentrations. Additionally, the liquid assay Maxilact LG $2000^{\mathrm{TM}}$ is more convenient to apply. Therefore, Maxilact LG $2000^{\mathrm{TM}}$ is recommended for the use in small scale lab experiments as a convenient and fast method resulting in high degrees of hydrolysis. Nevertheless, there are some major drawbacks. On the one hand, the enzymatic assay, in larger quantities in semi-industrial or industrial scale, will significantly contribute to the process costs and therefore antagonizes the efforts to reduce the price for PHA production. Economic appraisals done by industrial partners in the Wheypol project showed that Maxilact LG $2000^{\mathrm{TM}}$ would be under the top three cost factors of an overall production process from whey to PHA (personal communication Dr. Edgar Ahn, BDI - BioEnergy International AG, Austria). Therefore, it was reasonable to find cheap alternatives. Acidic hydrolysis of lactose for attaining the monosaccharides has been known since decades [39]. According to information from industrial project partners (personal communication Dr. Edgar Ahn), application of $\mathrm{H}_{2} \mathrm{SO}_{4}$, on the one hand, is cheaper when compared to $\mathrm{HCl}$ in large scale application. On the other hand, the surplus of $\mathrm{HCl}$ after hydrolysis will lead to $\mathrm{NaCl}$ after the necessary neutralization step with $\mathrm{NaOH}$, which can be directly used to prepare the highly saline cultivation medium needed for $H$. mediterranei. Therefore, the use of a mixture of $\mathrm{NaOH}$ and $\mathrm{KOH}$ for neutralization of the highly acidic hydrolysis broth in order to obtain the optimal ratio of alkaline ions $\left(\mathrm{Na}^{+}\right.$and $\mathrm{K}^{+}$) in the cultivation medium (see Materials and Methods section) is suggested. For non-halophile production strains, one should consider acid recovery by distillation after the hydrolysis step in order to safe material costs. A similar step was proposed to economically optimize $\mathrm{HCl}$-mediated hydrolysis of residues of the animal processing industry [49].

In all experimental setups, the microorganism accumulated a PHBHV copolyester with similar molar $3 \mathrm{HV}$ content in the range between 0.08 and $0.115 \mathrm{~mol} / \mathrm{mol}$. This is in accordance with previous findings for PHBHV production by this strain on other carbon sources, where $3 \mathrm{HV}$ molar fractions in PHBHV amounted to about 0.1 $\mathrm{mol} / \mathrm{mol}[4,17]$. Under similar conditions (no supply of structurally related $3 \mathrm{HV}$-precursors), most other microbial production strains accumulated the homopolyester PHB from lactose-derived substrates. As a remarkable exception, Povolo and colleagues [25] reported the production of PHBHV copolyesters with small amounts of $3 \mathrm{HV}$ by H. pseudoflava on lactose as carbon source. Replacing pure lactose by whey, even the incorporation of 4-hydroxybutyrate $(4 \mathrm{HB})$ building block was detected by these authors. The biopolymer, identified as poly(3HB-co-3HV-co-4HB) (PHBHV4HB) terpolyester, was attained at a concentration of $0.6 \mathrm{~g} / \mathrm{L}$. The same terpolyester was also produced by $H$. pseudoflava using lactose or sucrose plus additional supplementation of yeast extract. These findings were in contrast to previous results from the same group [24] and our own works [17], where recovered PHA samples from whey- and lactose based cultivation of $H$. pseudoflava contained $3 \mathrm{HB}$ as the only monomeric building block. Based on these findings, Povolo et al. [25] assumed that one or more unknown components, present in both yeast extract and in whey, might cause $4 \mathrm{HB}$ production and its following incorporation into the biopolyester. It will be highly intriguing to trace and identify these 4HB-precursor compound, together with the strain's unknown biochemical pathways responsible for production and assembly of copolyesters containing $3 \mathrm{HV}$ building blocks.

Regarding the results from cultivations on acid-catalysed whey permeate, direct comparison is possible with data published by Pais et al. [38], who used the same production strain (H. mediterranei) on $\mathrm{HCl}$-hydrolysed whey-permeate. These authors reported lower $D_{i}$ values ( 1.5 in comparison with 2.5 or 3.1 , respectively), which might be due to the different extraction method used by them (osmotic shock). In addition, these authors reported considerably lower $3 \mathrm{HV}$ fraction in their product (1.5\%) than presented in the study at hand (about $11 \%$ ), and slightly higher PHA concentration at the end of the experiment (7.5 g/L vs. 5.2 g/L in our study) [38] It is likely that these discrepancies originate from the differing media formulation used in their study, especially regarding the considerably higher availability of trace elements.

According to the results, enzymatic hydrolysis using the glycerolcontaining liquid enzyme assay Maxilact LG $2000^{\mathrm{TM}}$ has no negative impact on the molar mass of the polyester in comparison to acidcatalysed hydrolysis. It can be concluded that, due to the high salt requirements of $\mathrm{H}$. mediterranei and the lower costs, acidic hydrolysis should be preferred for large scale cultivation of this organism. At laboratory scale, the small amounts of enzyme required for substrate hydrolysis are not that tremendously cost demanding. Here, the Maxilact LG $2000^{\mathrm{TM}}$ assay performs advantageous due to its convenient and safe applicability. The final decision for enzymatic or chemical hydrolysis is very much dependent on the applied microorganism strain. If hydrolysis is required for cultivation of a halo-mesophile production strain, not tolerating high amounts of salts, it will be reasonable to hydrolyse lactose under acidic conditions, and to remove the salt content after neutralization by dialysis, or to apply acid recovery by distillation [48]. Based on the results reported by Obruca and colleagues [20] who demonstrated the positive impact of protease-hydrolysed whey retentate (proteinaceous whey fraction separated from the lactose-rich whey permeate by ultrafiltration) on growth of the PHA producing organism C. necator, one should consider a combined approach by using both the retentate fraction for growing the production strain $H$. mediterranei up to high biomass concentrations in a first fermentation phase; that approach 
Citation: Koller M, Puppi D, Chiellini F, Braunegg G (2016) Comparing Chemical and Enzymatic Hydrolysis of Whey Lactose to Generate Feedstocks for Haloarchaeal Poly(3-hydroxybutyrate-co-3-hydroxyvalerate) Biosynthesis. Int J Pharma Sci Res 3: 112. doi: http://dx.doi.org/10.15344/2394-1502/2016/112

Page 7 of 8

should be followed by supplying the carbon-rich hydrolysate of whey permeate in a second fermentation phase, which is characterized by nutritionally limited conditions. Here, one should consider that some ingredients of whey retentate, such as the enzymes lactoferrin (a transferrin with antibiotic and antiviral activity, important for the innate immune system), lactoperoxidase (a powerful antimicrobial compound), the immunologically active proteins IgG or osteopontin, as well as lactoferricin (displays anti-microbial and anti-cancer activity), are of significance in the pharmaceutical and medicinal field and even for food conservation; thus, they exhibit considerable market value [16].

\section{Conclusions}

Results of this study lead to the following conclusions:

D The glycerol-stabilized liquid $\beta$-galactosidase formulation Maxilact LG $2000^{\mathrm{TM}}$ provides a convenient method for lactose hydrolysis in highly concentrated whey permeate. The glycerol content does not result in lower molar masses of the produced biopolyester PHBHV.

$\checkmark$ Acidic hydrolysis of lactose in whey permeate under the investigated conditions results in high degrees of hydrolysis, both for $\mathrm{HCl}$ and $\mathrm{H}_{2} \mathrm{SO}_{4}$. That procedure constitutes an inexpensive alternative to enzymatic preparation of whey-based fermentation substrates.

D Because of the extremely low $\mathrm{pH}$-value during hydrolysis, the risk of microbial contamination of the hydrolysis set-up during hydrolysis is minimized when compared with enzymatic methods accomplished in the optimum range for various microbial species. The enzymatic approach can easily result in a highly infected hydrolysis product, this not only leads to substrate loss due to consumption by infecting organisms, but also endangers the monosepsis of the subsequent biotechnological cultivation. In contrast, the use of highly acidic conditions at high temperature $\left(90^{\circ} \mathrm{C}\right)$ leads to de facto sterile hydrolysed matter.

D Comparable final PHBHV concentrations and PHBHV quality (monomeric composition, molar mass and $D_{i}$ ) were obtained by the cultivation experiments of the different feedstocks (acid or enzymatic hydrolyzed whey, equimolar mixtures of glucose and galactose).

D Acidic hydrolysis contributes to the reduction of the overall process costs; according to calculations done by our industrial partners (personal communication Dr. Edgar Ahn), the method is economically advantageous when compared with enzymatic methods. In this context, the utilization of $\mathrm{HCl}$ instead of $\mathrm{H}_{2} \mathrm{SO}_{4}$ features some major advantages:

o Neutralization of the hydrolysate using $\mathrm{NaOH}$ results in high $\mathrm{NaCl}$ concentrations needed for cultivation of halophilic PHA production strains such as $H$. mediterranei which requires high amounts of $\mathrm{NaCl}$ for optimal cultivation conditions.

o HCl-catalyzed hydrolysis does not result in dark by-products. Dark product generated by hydrolysis with $\mathrm{H}_{2} \mathrm{SO}_{4}$ can conveniently be removed by adsorption on charcoal.

D If non-halophilic organisms are used, enzymatic hydrolysis will nevertheless be advantageous due to avoid unwanted salt concentrations. Unwanted salt concentrations could be removed, e.g., via dialysis.

\section{Competing Interests}

The authors declare that they have no conflict of interest in this work.

\section{Acknowledgements}

Prof. Emo Chiellini (BIOLab Research Group at University of Pisa, Italy) is greatly acknowledged for the critical reading of the manuscript.

\section{Funding}

The authors are grateful for the financial support from the European Commission by granting the project "Dairy industry waste as source for sustainable polymeric material production", Acronym WHEYPOL, GRD2-2000-30385. In this context, special credits go to our industrial project partners BDI - BioEnergy International AG, Grambach, Austria, for economic and engineering considerations, and Latterie Vicentine S.c.a., Bressanvido (VI), Italy, for producing and providing whey permeate from Asiago DOC cheese production used in this study.

\section{References}

1. Zinn M, Witholt B, Egli T (2001) Occurrence, synthesis and medical application of bacterial polyhydroxyalkanoate. Adv Drug Deliv Rev 53: 5-21.

2. Puppi D, Chiellini F, Piras AM, Chiellini E (2010) Polymeric materials for bone and cartilage repair. Prog Polym Sci 35: 403-440.

3. Brigham CJ, Sinskey AJ (2012) Applications of polyhydroxyalkanoates in the medical industry. Int J Biotechnol Wellness Ind 1:53-60.

4. Koller M, Hesse P, Bona R, Kutschera C, Atlić A, et al. (2007) Biosynthesis of high quality polyhydroxyalkanoate co-and terpolyesters for potential medical application by the archaeon Haloferax mediterranei. Macromol Sym 253: 33-39.

5. Tan GYA, Chen CL, Li L, Ge L, Wang L (2014) Start a research on biopolymer polyhydroxyalkanoate (PHA): a review. Polym 6: 706-754.

6. Koller M, Maršálek L, de Sousa Dias MM, Braunegg G (2016) Producing microbial polyhydroxyalkanoate (PHA) biopolyesters in a sustainable manner. N Biotechnol.

7. Beckers V, Poblete-Castro I, Tomasch J, Wittmann C (2016) Integrated analysis of gene expression and metabolic fluxes in PHA-producing Pseudomonas putida grown on glycerol. Microb Cell Fact 15: 73.

8. Hermann-Krauss C, Koller M, Muhr A, Fasl H, Stelzer F, et al. (2013) Archaeal production of polyhydroxyalkanoate (PHA) co- and terpolyesters from biodiesel industry-derived by-products. Archaea 2013: 129268.

9. Obruca S, Benesova P, Marsalek L, Marova I (2015) Use of lignocellulosic materials for PHA production. Chem Biochem Eng Quart 29: 135-144.

10. Haas C, Steinwandter V, Diaz De Apodaca E, Maestro Madurga B, Smerilli M, (2015) Production of PHB from chicory roots-comparison of three Cupriavidus necator strains. Chem Biochem Eng Quart 29: 99-112.

11. Drosg B, Fritz I, Gattermayr F, Silvestrini L (2015) Photo-autotrophic production of poly(hydroxyalkanoates) in cyanobacteria. Chem Biochem Eng Quart 29: 145-156.

12. Koller M, Marsalek L (2015) Cyanobacterial polyhydroxyalkanoate production: Status quo and quo vadis? Current Biotechnol 4: 464-480.

13. Khosravi-Darani K, Mokhtari ZB, Amai T, Tanaka K (2013) Microbial production of poly(hydroxybutyrate) from $\mathrm{C}_{1}$ carbon sources. Appl Microbiol Biotechnol 97: 1407-1424.

14. Muhr A, Rechberger EM, Salerno A, Reiterer A, Schiller M, et al. (2013) Biodegradable latexes from animal-derived waste: Biosynthesis and characterization of mcl-PHA accumulated by Ps. citronellolis. React Func Poly 73: 1391-1398.

15. Muhr A, Rechberger EM, Salerno A, Reiterer A, Malli K, et al. (2013) Novel description of mcl-PHA biosynthesis by Pseudomonas chlororaphis from animal-derived waste. J Biotechnol 165: 45-51.

16. Koller M, Salerno A, Muhr A, Reiterer A, Chiellini E, et al. (2012) Whey lactose as a raw material for microbial production of biodegradable polyesters. In: Hosam El-Din M. Saleh, Editor. Polyester Rijeka InTech 5192. 
Citation: Koller M, Puppi D, Chiellini F, Braunegg G (2016) Comparing Chemical and Enzymatic Hydrolysis of Whey Lactose to Generate Feedstocks for Haloarchaeal Poly(3-hydroxybutyrate-co-3-hydroxyvalerate) Biosynthesis. Int J Pharma Sci Res 3: 112. doi: http://dx.doi.org/10.15344/2394-1502/2016/112

Page 8 of 8

17. Koller M, Hesse P, Bona R, Kutschera C, Atlić A, et al. (2007) Potential of various archae and eubacterial strains as industrial polyhydroxyalkanoate producers from whey. Macromolecul Biosci 7: 218-226.

18. Koller M, Bona R, Chiellini E, Grillo Fernandes E, Horvat P, et al. (2008) Polyhydroxyalkanoate production from whey by Pseudomonas hydrogenovora. Bioresour Technol 99: 4854-4863.

19. Koller M (2015) Recycling of waste streams of the biotechnological poly(hydroxyalkanoate) production by Haloferax mediterranei on whey. Int J Polymer Sci 370164

20. Obruca S, Marova I, Melusova S, Mravcova L (2001) Production of polyhydroxyalkanoates from cheese whey employing Bacillus megaterium CCM 2037. Ann Microbiol 61: 947-953.

21. Obruca S, Benesova P, Oborna J, Marova I (2014) Application of protease-hydrolyzed whey as a complex nitrogen source to increase poly (3-hydroxybutyrate) production from oils by Cupriavidus necator. Biotechno Lett 36: 775-781.

22. Koller M, Atlić A, Gonzalez-Garcia Y, Kutschera C, Braunegg G (2008) Polyhydroxyalkanoate (PHA) biosynthesis from whey lactose. Macromo Symp 272: 87-92.

23. Audic JL, Chaufer B, Daufin G (2003) Non-food applications of milk components and dairy co-products: A review. Le Lait 83: 417-438.

24. Povolo S, Casella S (2003) Bacterial production of PHA from lactose and cheese whey permeate. Macromol Symp 197: 1-10.

25. Povolo S, Romanelli MG, Basaglia M, llieva VI, Corti A (2013) Polyhydroxyalkanoate biosynthesis by Hydrogenophaga pseudoflava DSM1034 from structurally unrelated carbon sources. New biotechnol 30: 629-634.

26. Yellore V, Desai A (1998) Production of poly-3-hydroxybutyrate from lactose and whey by Methylobacterium sp. ZP24. Lett Appl Microbiol 26: 391-394.

27. Ahn WS, Park SJ, Lee SY (2000) Production of Poly(3-hydroxybutyrate) by fed-batch culture of recombinant Escherichia coli with a highly concentrated whey solution. Appl Environ Microbiol 66: 3624-3627.

28. Ahn WS, Park SJ, Lee SY (2001) Production of poly(3-hydroxybutyrate) from whey by cell recycle fed-batch culture of recombinant Escherichia coli. Biotechnol Lett 23: 235-240.

29. Povolo S, Toffano P, Basaglia M, Casella S (2010) Polyhydroxyalkanoates production by engineered Cupriavidus necator from waste material containing lactose. Bioresour Technol 101: 7902-7907.

30. Koller M, Miranda de Sousa Dias M, Rodríguez-Contreras A, Kunaver M, Žagar E, et al. (2015) Liquefied wood as inexpensive precursorfeedstock for bio-mediated Incorporation of (R)-3-hydroxyvalerate into polyhydroxyalkanoates. Materials 8: 6543-6557.

31. Koller M, Salerno A, Strohmeier K, Schober S, Mittelbach M, et al. (2014) Novel precursors for production of 3-hydroxyvalerate-containing poly[(R)hydroxyalkanoate]s. Biocatal Biotransform 32: 161-167.

32. Han J, Zhang F, Hou J, Liu X, Li M, et al. (2012) Complete genome sequence of the metabolically versatile halophilic archaeon Haloferax mediterranei, a poly(3-hydroxybutyrate-co-3-hydroxyvalerate) producer. $J$ Bacteriol 194: 4463-4464.

33. Han J, Hou J, Zhang F, Ai G, Li M, at al. (2013) Multiple propiony coenzyme A-supplying pathways for production of the bioplastic poly(3 hydroxybutyrate-co-3-hydroxyvalerate) in Haloferax mediterranei. Appl Environ Microbiol 79: 2922-2931.

34. Huang TY, Duan KJ, Huang SY, Chen CW (2006) Production of polyhydroxyalkanoates from inexpensive extruded rice bran and starch by Haloferax mediterranei. J Ind Microbiol Biotechnol 33: 701-706.

35. Bhattacharyya A, Pramanik A, Maji SK, Haldar S, Mukhopadhyay UK, et al. (2012) Utilization of vinasse for production of poly-3-(hydroxybutyrate-cohydroxyvalerate) by Haloferax mediterranei. AMB Express 2: 1.

36. Bhattacharyya A, Saha J, Haldar S, Bhowmic A, Mukhopadhyay UK, et al. (2014) Production of poly-3-(hydroxybutyrate-co-hydroxyvalerate) by Haloferax mediterranei using rice-based ethanol stillage with simultaneous recovery and re-use of medium salts. Extremophiles 18: 463-470.

37. Alsafadi D, Al-Mashaqbeh O (2016) A one-stage cultivation process for the production of poly-3-(hydroxybutyrate-co-hydroxyvalerate) from olive mil wastewater by Haloferax mediterranei. N Biotechnol S1871-6784: 3002030026 .
38. Pais J, Serafim LS, Freitas F, Reis MA (2016) Conversion of cheese whey into poly(3-hydroxybutyrate-co-3-hydroxyvalerate) by Haloferax mediterranei. N Biotechnol 33: 224-230.

39. Whittier EO (1925) Lactose: A Review. Chemical Reviews 2: 85-125.

40. Santos A, Ladero M, Garcia-Ochoa F (1998) Kinetic modeling of lactose hydrolysis by a $\beta$-galactosidase from Kluyveromices fragilis. Enzyme Microbial Technol 22: 558-567.

41. Ladero M, Santos A, García-Ochoa F (2000) Kinetic modeling of lactose hydrolysis with an immobilized beta-galactosidase from Kluyveromyces fragilis. Enzyme Microb Technol 27: 583-592.

42. Roy I, Gupta MN (2003) Lactose hydrolysis by Lactozym ${ }^{\mathrm{TM}}$ immobilized on cellulose beads in batch and fluidized bed modes. Process Biochem 39: 325-332.

43. Koller M, Sandholzer D, Salerno A, Braunegg G, Narodoslawsky M (2013) Biopolymer from industrial residues: Life cycle assessment of poly(hydroxyalkanoates) from whey. Resource Conserv Recycl 73: 64-71.

44. Madden LA, Anderson AJ, Shah DT, Asrar J (1999) Chain termination in polyhydroxyalkanoate synthesis: involvement of exogenous hydroxycompounds as chain transfer agents. Int J Bio Macromol 25: 43-53.

45. Online Ressource: MAXILACT®LG 2000.

46. Trainotti L, Spinello R, Piovan A, Spolaore S, Casadoro G (2001) $\beta$-Galactosidases with a lectin-like domain are expressed in strawberry. $J$ Exp Bot 52: 1635-1645.

47. Koller M, Bona R, Hermann C, Horvat P, Martinz J, et al. (2005) Biotechnological production of poly(3-hydroxybutyrate) with Wautersia eutropha by application of green grass juice and silage juice as additional complex substrates. Biocatal Biotransform 23: 329-337.

48. Braunegg G, Sonnleitner BY, Lafferty RM (1978) A rapid gas chromatographic method for the determination of poly- $\beta$-hydroxybutyric acid in microbial biomass. Euro J Appl Microbiol Biotechnol 6: 29-37.

49. Titz M, Kettl KH, Shahzad K, Koller M, Schnitzer H, et al. (2012) Process optimization for efficient biomediated PHA production from animal-based waste streams. Clean Technol Environ Policy 14: 495-503. 